\title{
Reflexões sobre ciência e ética
}

\author{
Maria Thereza Prost \\ Museu Paraense Emílio Goeldi. Belém, Pará, Brasil
}

O termo 'ética' vem do grego, referindo-se a assuntos morais e a tipos de ação (costumes). Tomada como disciplina puramente humana, a Ética é um ramo da filosofia porque examina e estuda uma parte da experiência humana referente à vontade responsável (livre arbítrio) e à conduta moral (valores construtivos ou não). A ética pode ser, portanto, definida como um conjunto de valores morais que orientam a vida humana. Por esse motivo, existem várias visões em diferentes segmentos da sociedade, visto depender da evolução de cada indivíduo e do que ele traz como equilíbrio emocional e espiritual.

Em termos de ciência, todos sabemos que, hoje, há a necessidade premente de uma constante atualização, pois ainda que os princípios fundamentais sejam os mesmos, as técnicas evoluem e os conhecimentos se aperfeiçoam. Mas é preciso também relembrar o óbvio, ou seja, que toda profissão inclui deveres e responsabilidades. Assim, o profissional (pesquisador, professor etc.) precisa dedicar-se plenamente à pesquisa científica, tendo como objetivo o bem comum. Estima-se que deve ser um homem (ou uma mulher) de consciência, não almejando somente 'subir' na carreira, obter garantias materiais, vantagens, dinheiro, mordomias e prestígio pessoal. Todo aquele que tem uma visão correta de sua dignidade profissional respeita a si mesmo, em sua vida particular e pública.

Devemos ter, simultaneamente, uma visão holística do país no qual exercemos nosso trabalho, estando cientes que o crescimento científico, econômico e social do Brasil no contexto da globalização (que interessa a todos nós, pois, como dizia um conhecido geógrafo, "o mundo é uma aldeia") se faz por meio de uma identidade nacional singular de índole política, social e racial, mesmo se nos encontramos no seio de conflitos inerentes aos países emergentes, como a violação de direitos humanos, a violência no campo e na cidade, a miséria e a fome, o uso inadequado de recursos naturais, a corrupção, ganância, intolerância e preconceitos. Nesse contexto, as instituições de pesquisa e de ensino precisam - imperativamente e sem nenhuma dúvida - ser sítios de mudanças e inovações construtivas, vinculando potencialidades humanas que aliem os princípios éticos à concepção científica e tecnológica.

Estimo, como pesquisadora e orientadora, que nosso dever de base é transmitir, o melhor possível, o conhecimento adquirido ao longo de nossa vida profissional em instituições de renome (como o Museu Paraense Emílio Goeldi, órgão do Ministério da Ciência, Tecnologia e Inovação), formando o que se conhece como 'recursos' humanos. Mas é preciso, sobretudo, ir além da noção de 'recursos', procurando desenvolver, com empenho, as aptidões naturais e humanas dos estudantes, como a reflexão sistemática, o espírito crítico e o desejo de progredir, tendo sempre a ética na pesquisa como suporte. Neste particular, condenamos fortemente o plágio, que, infelizmente, é ainda uma realidade no meio científico, mesmo em nível de Doutorado (como denunciado recentemente na Alemanha). A desonestidade e a fraude

PROST, Maria Thereza, 2011. Reflexões sobre ciência e ética. Boletim do Museu Paraense Emílio Goeldi. Ciências Naturais 6(2): 215-218. Autor para correspondência: Maria Thereza Prost. Museu Paraense Emílio Goeldi. Av. Perimetral, 1091. Terra Firme. Belém, PA, Brasil. CEP 66077-530 (prost@museu-goeldi.br).

Recebido em 13/07/2011

Aprovado em 23/08/2011

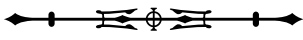


ocorrem também frequentemente com o uso incorreto da internet, ou ainda com pagamentos a terceiros para a realização de trabalhos universitários, atitudes corruptas utilizadas por alguns como um "jeito (meio) esperto, cômodo e eficaz" para atingir seus fins. Para coibir tais abusos, é primordial o acompanhamento e o controle constantes da progressão e dos resultados dos trabalhos pelos orientadores e pelos Colegiados de Pós-Graduação.

Ainda na visão holística de nossa profissão e na qualidade de cidadão, é coerente e legítimo o fato de que cada um de nós (e todo brasileiro) aspire viver em uma sociedade política multi-étnica, justa, plural, solidária e respeitosa das diferenças, que atenda às suas necessidades básicas, como o direito à educação e ampliação constante de seus conhecimentos, saúde, liberdade, igualdade, fraternidade e dignidade. Com efeito, os governos ditatoriais levam à 'desnaturalização' do Estado e a uma aculturação negativa, com procedimentos repressivos, imorais, ilegítimos, intolerantes, discriminatórios, antiéticos e ilegais, na maioria das vezes, exercidos na certeza da impunidade. Neste particular, cada um de nós, tem o dever e a obrigação de conhecer a política pública (e os políticos) de seu país, analisar seus debates e decisões (exemplos, entre outros: a Política Nacional em Ciência, Tecnologia e Informação, o Novo Código Florestal, o Zoneamento Ecológico-Econômico, as Unidades de Proteção Ambiental etc.), além de denunciar, não justificar nem ser conivente com atos antiéticos (como a sonegação fiscal, a venda de votos, os 'caixas dois' de financiamento de campanhas e as 'propinas' voluminosas escondidas em bolsas, malas, roupas etc.), fazendo a escolha criteriosa pelo voto em representantes com 'ficha limpa'. Quanto aos pesquisadores, cabe contribuírem com seus trabalhos, sem postergar tempo e esforços para o planejamento, a inovação e o desenvolvimento sustentável, por meio de projetos em rede, comissões consultivas, estudos interdisciplinares ambientais, pesquisas participativas de gênero, planos de manejo, reservas extrativistas etc. Estimo que essas atividades, muitas vezes ignoradas ou minimizadas nos processos formais de avaliação de pesquisadores pela Academia e por órgãos ministeriais, deveriam ser bem mais valorizadas em suas pontuações, tendo como 'pano de fundo' as relações entre ética e desenvolvimento científico.

É necessário, igualmente, estar atento a um outro problema importante, a saber, o fato de que há, no plano existencial, ambiguidades e paradoxos entre ciência e ética referentes ao contínuo progresso científico e tecnológico e suas aplicações. São exemplos: o uso militar da energia nuclear, as justificativas tecnológicas de 'guerras limpas', a degradação acelerada do meio ambiente (desmatamento, grilagem de terras com intoleráveis conflitos e assassinatos no campo, poluição e degradação de solos, terras aráveis e recursos aquíferos etc.). Valores éticos (e religiosos) são frequentemente apresentados e discutidos na sociedade pelos meios de comunicação de grande audiência da mídia escrita e falada (artigos, documentários, entrevistas, vídeos, novelas, filmes, mesas-redondas, debates etc.), exercendo influência nos modos de pensar das pessoas e nas modalidades de sociedades mais permissíveis ou mais conservadoras. Nesse contexto, a ciência tenta discernir, com sabedoria, o melhor para o ser humano. O pesquisador, qualquer que seja sua área de atuação, tem que adotar a ética como suporte de seu trabalho, com a responsabilidade e a integridade que são inerentes à atividade científica.

Enfim, cabe ainda ressaltar que a ciência contemporânea é um empreendimento social, cujo sucesso depende muito dos mecanismos de comunicação científica. Neste particular, as publicações constituem um dos pilares da produção do conhecimento, como preconizado, por exemplo, pela Coordenação de Aperfeiçoamento de Pessoal de Nível Superior (CAPES). Mas acreditamos que um dos processos principais, nesse contexto, deve ser o da credibilização do material publicado: com efeito, a crescente pressão profissional para a publicação, aliada à grande aceleração da produção cientíica, têm gerado um número crescente de submissão de artigos e, consequentemente, um acentuado 
decréscimo das taxas de aceitação em revistas de nível A, situação que gera desconforto latente em largos setores da comunidade científica. Neste particular, Jorge Marques da Silva, em seu artigo sobre "Aspectos éticos e funcionais da publicação científica" (2006), considera que a ética na ciência deve responder a problemas internos (atividade científica) e externos (relações entre ciência e sociedade). O primeiro caso inclui a questão já discutida da fraude científica e de seus limites, a atribuição de autoria de publicações e de patentes, além do sistema de revisão pelos pares. A vertente externa aborda problemas técnico-científicos com maiores impactos nas populações (por exemplo, técnicas biomédicas e de $A D N$, tecnologia nuclear etc.), vertente que gerou, em parte, a Ética Ambiental.

Essa pressão para a publicação resulta do número crescente de grupos de pesquisadores (por vezes, competindo por recursos financeiros limitados) e pela obrigação de publicar, tendo em vista a avaliação de seu desempenho profissional pela Academia. Por um lado, o número de artigos submetidos a revistas de tipo $\mathrm{A}$ (aceitos ou não) é grande. Por outro lado, há frequente demora da resposta de corpos editoriais (tanto para artigos de nível A ou B, como para livros), além do problema da existência, em determinados países e regiões, de equipes editoriais subdimensionadas, com revisores menos experientes e com fragilidade do sistema de revisão na detecção de fraudes.

Jorge Marques da Silva estima que a revisão pelos pares, apesar de suas deficiências, continua a ser o pilar central da arbitragem científica. "Importa, contudo, estudar e compreender as suas dinâmicas, e alcançar um entendimento aprofundado das especificidades que apresentam as diferentes áreas do conhecimento" (Silva, 2006, p. 30). Transversalmente, é necessário consolidar a exigência ética do processo e repensar as condições de anonimato, aumentando a responsabilização de editores e revisores, e garantindo aos autores uma avaliação mais justa.

Antes de concluir, gostaríamos de apresentar duas curtas reflexões a partir de livros de dois autores contemporâneos, Roberto DaMatta, conhecido antropólogo e professor titular do Departamento de Sociologia e Política da Pontifícia Universidade Católica do Rio de Janeiro (PUCRJ), e José Saramago, escritor português, prêmio Nobel de literatura em 1998, falecido recentemente em Lazarote, nas ilhas Canárias. Roberto DaMatta, procurando analisar as mentalidades pelas ações por ela determinadas, escreveu, a pedido do governo do Espírito Santo, o livro "Fé em Deus e Pé na Tábua" (2010), analisando o comportamento, na vida cotidiana, de motoristas e condutores na Grande Vitória e no interior do estado (em carros particulares, caminhões, motocicletas, táxis, ciclistas e agentes de trânsito), além dos pedestres. $\bigcirc$ objetivo do autor foi explicar as razões de uma mentalidade pelas ações (éticas ou não) por ela determinada, ressaltando uma dupla contradição: como o espaço igualitário da rua torna-se hierarquizado e quais são as consequências. Roberto DaMatta insiste na necessidade de democratizar a rua, fazendo que ela, como a casa, seja submetida a um código igualitário, ponto principal de toda sociedade republicana e liberal, fundada no confronto, análise e síntese de ideias, de partidos e, em seu centro, na divisão (e limites) de poderes, cujo principal fundamento é a consciência.

Quanto a Saramago, de sua extensa e extraordinária obra, salienta-se, entre outros, o "Ensaio sobre a cegueira" (1995), livro alegórico cuja narrativa é de uma dureza inusitada, com cenas dantescas e apocalípticas de exploração econômica, enfrentamento físico e opressão sexual entre cegos, vítimas de uma epidemia que atinge, com intensidade, alta frequência e velocidade toda uma cidade, formando verdadeiros guetos de violência e exclusão. O genial escritor demonstra, com seu singular 'estilo saramaguiano', que estamos cada vez mais cegos, pois cada vez menos queremos ver. "No fundo, o que este livro quer dizer é, precisamente, que todos nós somos cegos pela Razão" (Marques Lopes, 1969). No contexto dos atuais confrontos ambientais, étnicos, políticos e científicos do mundo em que vivemos, o pesquisador não pode ser "cego pela razão", sua pesquisa deve ser digna, honesta e ética, primando pela lucidez. 
No cotidiano, lembremo-nos que para tudo que fazemos existem regras. É importante que aprendamos a estabelecer harmoniosamente o nosso espaço, em casa, na rua, no bairro, na escola, no trabalho, na instituição, entre amigos e camaradas. A recomendação mais importante, em qualquer situação, é dar o exemplo, se fazer respeitar (e respeitar os demais, qualquer que seja sua posição e função) como pessoa e como profissional.

Em síntese,

a ampliação dos benefícios, para toda a sociedade, dos conhecimentos científicos e tecnológicos depende da cultura, da qualidade da educação e de sua universalização. Uma sociedade consciente desse significado é capaz de compreender e apoiar os esforços requeridos para a capacitação em CT\&I e tem melhores condições de decidir sobre alternativas e limites éticos para a pesquisa e o desenvolvimento (Brasil, 2002).

\section{REFERÊNCIAS}

BRASIL, 2002. Ministério da Ciência e Tecnologia (MCT). Livro Branco - Ciência, Tecnologia e Inovação: 1-80. Ministério de Ciência e Tecnologia, Brasilia.

DAMATTA, R., 2010. Fé em Deus e Pé na Tábua (o trânsito enlouquece o Brasil): 1-191. Ed. Rocco Ltda., Rio de Janeiro.

MARQUES LOPES, J., 1969. Saramago - biografia: 1-246. Ed. Leya, São Paulo.

SILVA, J. M., 2006. Aspectos éticos e funcionais da publicação científica: passado, presente e futuro. Interacções (3): 19-31. 